\title{
Deformation Prediction of Plate Line Rolling Forming Based on Inherent Strain Method
}

\author{
Changcheng Hu, ${ }^{1}$ Yao Zhao, ${ }^{1,2}$ and Guoyuan Tang ${ }^{1}$ \\ ${ }^{1}$ School of Naval Architecture and Ocean Engineering, Huazhong University of Science and Technology, Wuhan 430074, China \\ ${ }^{2}$ Collaborative Innovation Center for Advanced Ship and Deep-Sea Exploration (CISSE), Shanghai 200240, China
}

Correspondence should be addressed to Yao Zhao; yzhaozzz@hust.edu.cn

Received 20 December 2016; Revised 14 February 2017; Accepted 16 February 2017; Published 20 March 2017

Academic Editor: Zhen-Lai Han

Copyright (C) 2017 Changcheng Hu et al. This is an open access article distributed under the Creative Commons Attribution License, which permits unrestricted use, distribution, and reproduction in any medium, provided the original work is properly cited.

Inherent strain method has been widely used as a forecasting and computing method for welding deformation of large complicated structures and further applied to the research of line heating forming. Mechanical forming is a common ship-hull plate forming method, for which deformation prediction still depends mainly on elastoplastic finite element method. This paper researched the application of inherent strain method to plate line rolling forming, a common mechanical forming method, and then compared the results of inherent strain method and elastoplastic finite element method, proving the applicability of inherent strain method, providing a method for fast, accurate forecasting of distortion in plate line rolling and formation of automation equipment.

\section{Introduction}

3D curved plates are widely used in aerospace, shipbuilding, and other industries; in order to achieve the fast production and flexible manufacturing of 3D curved plates, lots of researchers have made a large number of researches and attempts. The common line heating forming [1], peen forming gradually developed and applied in recent years [2], local line rolling forming, single-point incremental forming [3], and multipoint forming all are available for the rapid, precise forming of 3D curved plates. At present, the forming path and parameters have been determined for strain distributionbased line heating forming, but local line rolling forming still relies on artificial experience, which has an intervening effect on the former, while computer-driven automated line rolling forming has not been realized yet.

The inherent strain method derived from large structural welding deformation prediction has become a research hotspot. Some scholars introduced inherent strain theory into the research of strain and deformation in hot working process, making breakthrough progress in both hull welding deformation control and line heating and bending forming of hull plate $[4,5]$. As a common bending forming way of shell plate, line rolling forming has some characteristics similar to those of line heating forming, so we can consider applying the theory of inherent strain to the research of strain and deformation in line rolling forming.

This paper proposed forecasting the strain and deformation in line rolling forming based on inherent strain method. The paper first numerically simulated local line rolling forming by elastoplastic finite element method, to analyze its bending forming characteristics, and then input inherent strain to a plate model in the form of initial strain for simple elastic computing based on the thought of inherent strain, the results showing that inherent strain method could predict the strain and deformation in line rolling and bending forming quickly and precisely, so as to help build a relationship between forming shape and forming path as well as process parameters. This would be beneficial in promoting the development of research on the automated line rolling forming of shell plate.

\section{FEM of Local Line Rolling Forming}

Large deformation elastoplastic finite element method can accurately simulate the changing process of stress-strain field and displacement field in the entire analysis procedure. It can be used to calculate and analyze the strain distribution characteristics of line rolling forming and adopted as an object validated by inherent strain method. 
In line rolling forming process there exist a number of nonlinear problems such as large deformation, material elastic-plasticity, and contact problems, and as the rollers roll on the plate, the plate keeps entering and exiting the rolling zone; namely, the forming and springback are occurring at the same time. Considering the above characteristics of rolling forming, commercial software ABAQUS/Standard is adopted for finite element calculation, since it is very suitable for nonlinear problem solving. Despite a relatively long calculation time required, this method has higher accuracy compared with ABAQUS/Explicit, and it is more applicable to the simulation of springback [6]. Finite element simulation is based on load increment calculation, with each simulation process divided into multiple load increments. The finite element simulation in this paper covers the following loading steps.

Step 1. Assemble the components (plate and rollers) according to the geometrical relationship (Figure 1) and set a contact surface and contact properties between processed plate and rollers.

Step 2. Apply an artificially set $Z$-axial negative minimum displacement load to the upper roller with the lower roller location unchanged and carry out numerical simulation by load increment computation, to establish contact between the rollers and the processed plate.

Step 3. The upper roller applies an appropriate displacement load to the plate, and causes local deformation to it.

Step 4. Apply an angular displacement load to the lower roller with the location of the upper and lower rollers unchanged. The contact friction leads to a change in the relative location of the plate and rollers, and the plate gradually enters the rolling zone. In this process, the plate keeps entering and exiting the rolling zone, accompanied by forming and springback. After the end of rolling on the entire forming path, the upper and lower rollers are removed gradually away from the plate. The contact action between rollers and plate gradually decreases in this process, and the plate springs back as well until it is separated from the rollers completely.

The elastoplastic finite element model established is shown in Figure 1. The size of machined plate is $2000 \mathrm{~mm}$ $\times 1000 \mathrm{~mm} \times 20 \mathrm{~mm}$, modulus of elasticity is $2.1 \times 10^{11} \mathrm{~Pa}$, and Poisson's ratio is 0.3 . In elastoplastic analysis, the linear hardening model for plate is adopted, and the geometrical shape and dimension of roller are shown in Figure 2. The defined forming path is that machining is carried out on the center line of plate along the plate length direction, the position of lower roller remains unchanged, and the lower roller can rotate around its axis in order to drive the plate to move, while the upper roller can move along $z$-axis so as to impose a local load on the plate. Press amount of roller is set equal to $4 \mathrm{~mm}$ in this paper. A contact action is established between rollers and machined plate, upper and lower rollers are set as rigid bodies, machined plate is set as a deformable body, the friction coefficient between the two is equal to 0.15 , and the problem of contact between rollers and machined plate is solved by test-check iterating method. Fine grids are

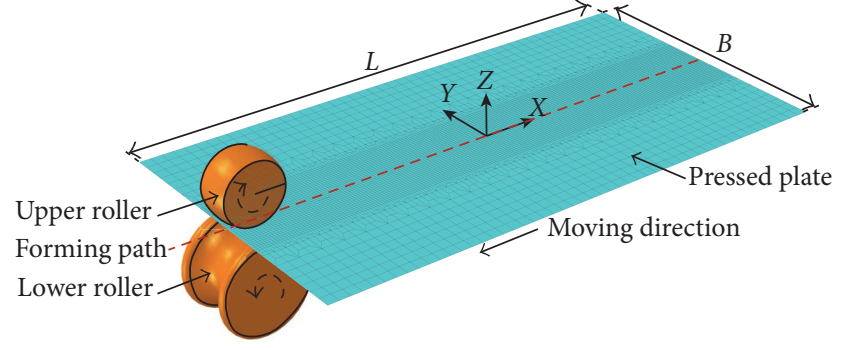

Figure 1: Finite element model and grid generation.

generated around the forming path, and the grid size is $10 \mathrm{~mm}$ $\times 10 \mathrm{~mm}$. Sparse grids are generated in the locations far away from the forming path, and the grid size is $40 \mathrm{~mm} \times 40 \mathrm{~mm}$. Transition grids are generated between both kinds of grids, and the entire model consists of 7,500 elements and 7,597 nodes. As rollers rotate, a change takes place to the relative position of rollers and plate, and rollers move gradually on plate to form a forming path to deform the whole plate.

In the process of line rolling forming, springback of plate is of great importance and it is necessary to predict the mechanical springback. In the simulation, the relative gap and contact pressure between the roller and the plate is used to determine whether they are in contact or separated. After the static load is removed, it is assumed that the roller is separated from the pressed plate, and the resilient calculation will be carried out.

In order to verify the applicability of this method, a three-dimensional elastoplastic finite element calculation is performed to compare with the experimental results in [7] that contains the above-mentioned similar computational features. The comparison results are shown in Table 1 , where $2 a$ is the distance between support rolls, $d_{Z}$ is the forming depth, $\mathrm{Rb}$ is the radius of curvature of the workpiece boundary, $(\mathrm{Rb})_{\operatorname{EXP}}$ refer to the experimental results, and $(\mathrm{Rb})_{\mathrm{CAL}}$ refer to the FEM results. Excellent correlation between the numerical results and the experimental results is revealed in Table 1, demonstrating the feasibility of the threedimensional elastoplastic finite element method.

Adopt elastoplastic finite element method for numerical simulation computation of the model, and then integrate the plastic strain obtained by calculation along the plate thickness, obtaining in-plane strain and bending strain:

$$
\begin{aligned}
\varepsilon_{i j}^{m}(x, y) & =\frac{1}{h} \int_{-h / 2}^{h / 2} \varepsilon_{i j}(x, y, z) d z, \\
\varepsilon_{i j}^{b}(x, y) & =\frac{2}{h^{2}} \int_{-h / 2}^{h / 2} z\left(\varepsilon_{i j}(x, y, z)-\varepsilon_{i j}^{m}(x, y)\right) d z,
\end{aligned}
$$

where $\varepsilon_{i j}^{m}(x, y)$ denotes in-plane strain, $\varepsilon_{i j}^{b}(x, y)$ denotes bending strain, and $h$ denotes thickness. Since $h / L=$ 0.02 , which meets the assumed condition of thin plate, it could be approximately considered that $\varepsilon_{z}, \varepsilon_{y z}, \varepsilon_{z x}$ have little 

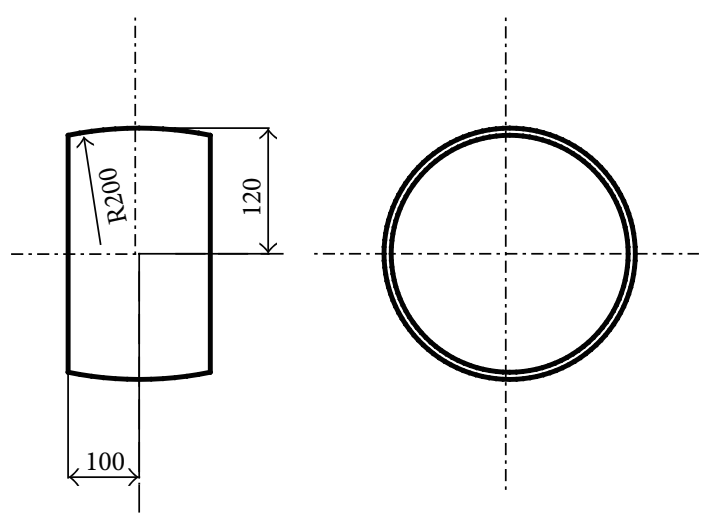

(a)
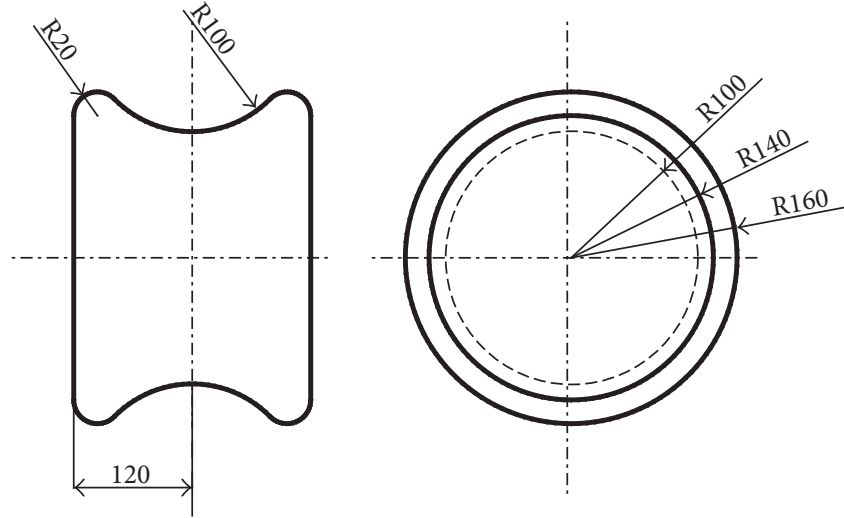

(b)

FIGURE 2: Shape and dimension of upper/lower roller. (a) Upper roller; (b) lower roller.

TABLE 1: Comparison of results between FEM and experiment [7].

\begin{tabular}{lccccc}
\hline Number & $2 a(\mathrm{~mm})$ & $d_{Z}(\mathrm{~mm})$ & $(\mathrm{Rb})_{\mathrm{EXP}}$ & \multicolumn{2}{c}{$(\mathrm{Rb})$} \\
$(\mathrm{Rb})_{\mathrm{CAL}}$ & 149.3 & 0.95 \\
2 & 40 & 1.2 & 142.4 & 198.5 & 0.96 \\
3 & 45 & 1.2 & 191.8 & 134.2 & 0.93 \\
4 & 40 & 1.4 & 125.4 & 172.7 & 0.97 \\
\hline
\end{tabular}

effect on deformation, and meanwhile $\varepsilon_{x x}, \varepsilon_{y y}, \gamma_{x y}$ could be transformed to principal strain:

$$
\begin{aligned}
& \varepsilon_{1}=\frac{\varepsilon_{x x}+\varepsilon_{y y}}{2}+\frac{1}{2} \sqrt{\left(\varepsilon_{x x}-\varepsilon_{y y}\right)^{2}+\varepsilon_{x y}^{2},} \\
& \varepsilon_{2}=\frac{\varepsilon_{x x}+\varepsilon_{y y}}{2}-\frac{1}{2} \sqrt{\left(\varepsilon_{x x}-\varepsilon_{y y}\right)^{2}+\varepsilon_{x y}^{2},} \\
& \alpha=-\frac{1}{2} \arctan \left(\frac{\gamma_{x y}}{\varepsilon_{x x}-\varepsilon_{y y}}\right),
\end{aligned}
$$

where $\varepsilon_{1}, \varepsilon_{2}$ are the first and second principal strain, respectively, and $\alpha$ represents the direction angle of principal strain. Calculate the plastic strain obtained by elastoplastic finite element method according to formula (1) and (2), getting inplane strain and bending strain distribution maps of plate, as shown in Figure 3.

As can be seen in Figure 3, similar to line heating forming, the plastic strains generated by local line rolling forming are mainly distributed around the forming path; strains are distributed stably along the forming path; both in-plane strain and bending strain are perpendicular to the forming path. However, plastic strain and residual stress distributions that are generated by line rolling bending forming and line heating forming, respectively, are different; the inherent strain method is actually an elastic calculation. Therefore, strain and stress distribution differences of the above two forming methods take form only when the inherent strain method is adopted to predict the global deformation of machined plate. Considering this, it is necessary to define the applicability of the inherent strain method in a condition of multiple forming paths.

\section{Impacts of Multiple Forming Paths}

If minor strain shown in Figure 3 is ignored, shrinkage and bending strains perpendicular to the direction of a single forming path are mainly generated by such a path. In order to realize forming of complex 3D curved plate, multiple forming paths should be applied onto the machined plate. These forming paths can be parallel or crossed, and so on. If a forming path is able to generate plastic strain within a region near the forming path on plate after the completion of line rolling forming, residual stress can be also formed simultaneously. Therefore, other subsequent forming paths may exert influences on the shape of machined plate due to residual stress and plastic strain. As shape of the machined plate depends on plastic strain distribution, coupling of plastic strains among multiple forming paths is able to affect prediction accuracy of the inherent strain method. Below, strain distribution of forming paths parallel or crossed are analyzed.

Elastoplastic incremental calculation is employed. Computing results are acquired under the circumstance that load, unloading, and springback calculations have been completed for Path 1, which is followed by Path 2 load, unloading, and springback calculations based on all mechanical conditions remaining on Path 1.

In Figure 4(a), line rolling forming is firstly loaded along forming Path 1 , making plate deformed. In this process, residual stress and plastic strain are generated in the plate. Then, line rolling forming load is carried out along the forming 


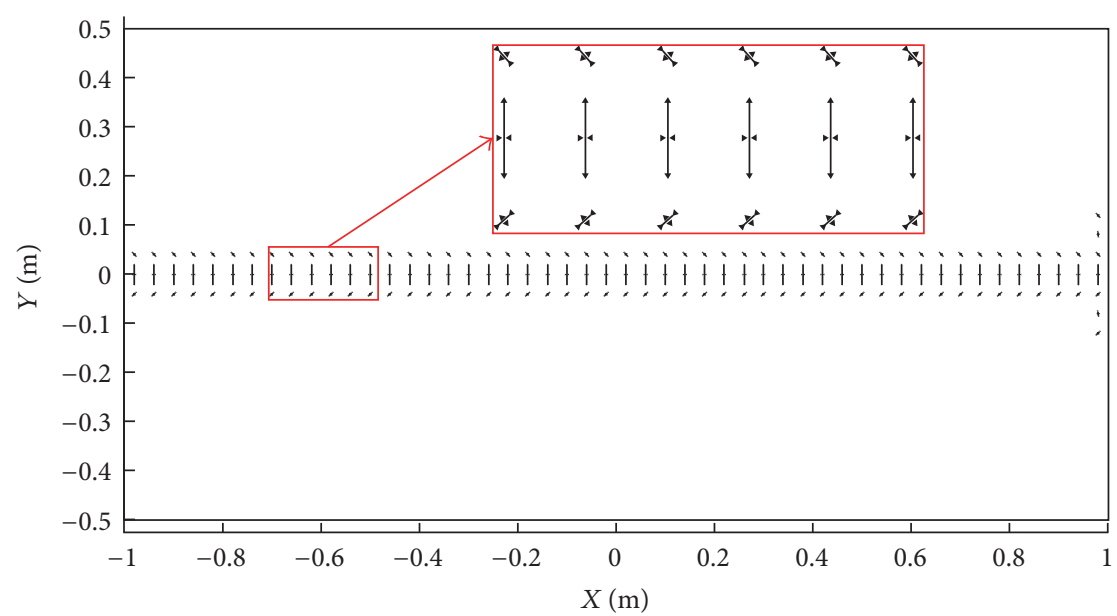

(a)

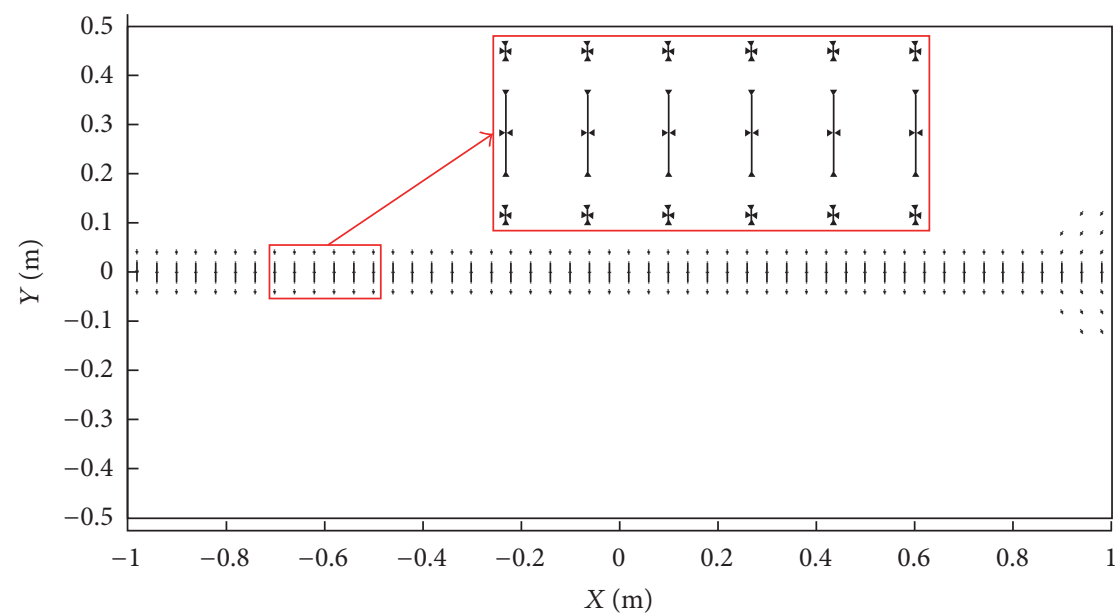

(b)

Figure 3: In-plane strain and bending strain obtained by line rolling forming. (a) Distribution of in-plane strain (maximum value $=0.003$ ); (b) distribution of bending strain (maximum value $=0.024$ ).

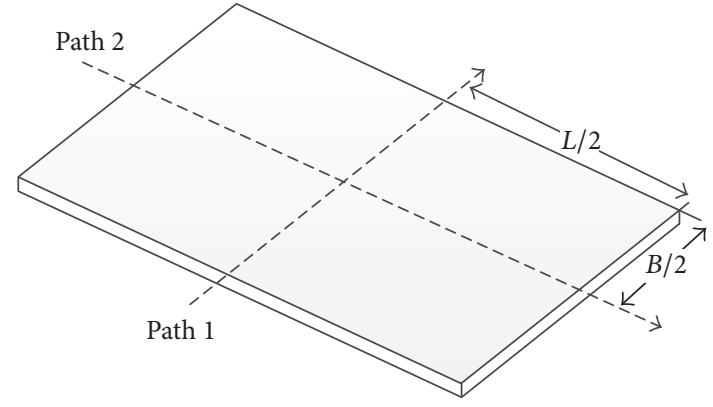

(a)

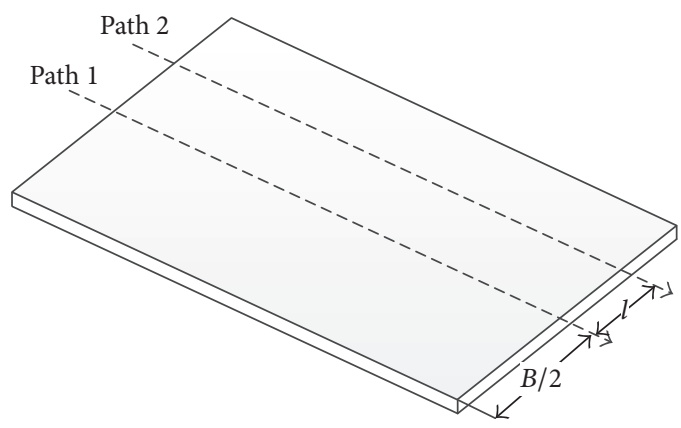

(b)

Figure 4: Positional relations of forming paths. (a) crossed; (b) parallel.

Path 2, used to investigate whether residual stress and plastic strain already in the plate exert any influence on the second rolling load. In other words, it should be made clear that whether plastic strain distribution obtained by forming Path 2 changes due to load of forming Path 1 . In addition, it is also utilized to investigate whether changes occur to results of plastic strain generated by forming Path 1 because of actions imposed by the forming Path 2, which is to be sure whether mutual influence exists between plastic strains, respectively, generated by two forming paths. With an aim to compare 


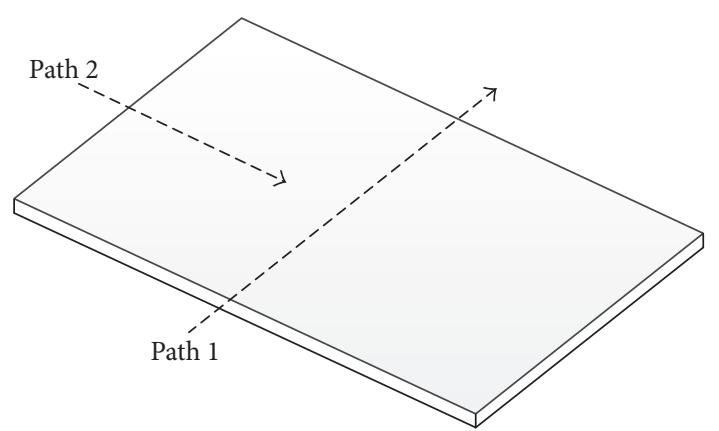

(a)

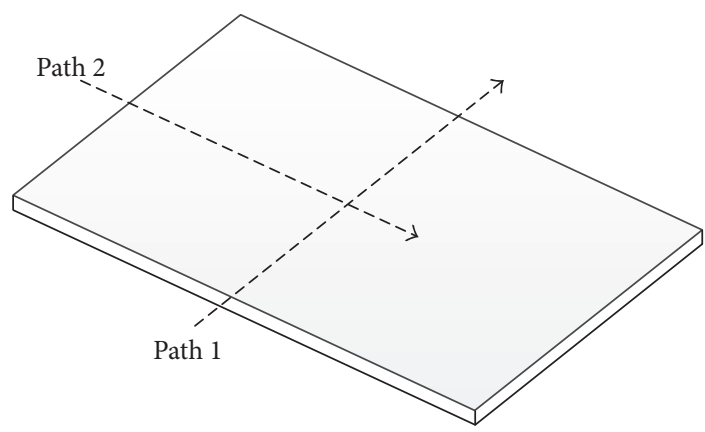

(c)

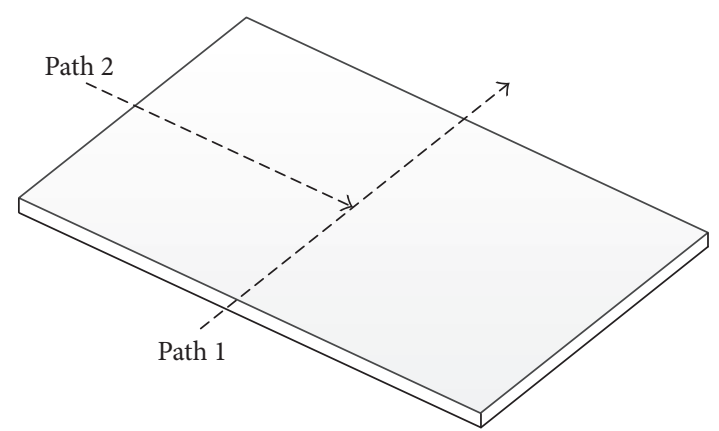

(b)

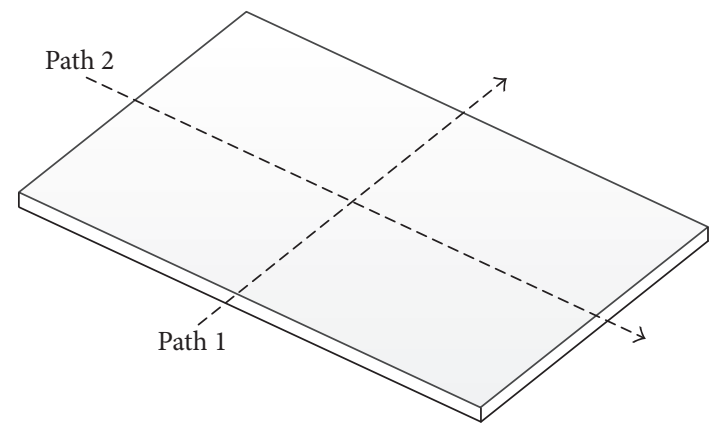

(d)

FIGURE 5: Four states of crossed forming paths. (a) Uncrossed paths; (b) half crossed paths; (c) partial crossed paths; (d) crossed paths.

generation process of mutual influences between two forming paths, four states of crossed forming paths are selected for numerical calculation, as shown in Figure 5. In detail, the press amount of every roller corresponding to each path is $4 \mathrm{~mm}$. Figure 5(a) indicates that Path 2 begins to move towards the midpoint of plate from the edge of it; and, when it arrives at the plastic zone generated by Path 1, load stops. Figure 5(b) signifies that load stops as soon as Path 2 arrives at the midpoint of plate through movement. In Figure 5(c), Path 2 moves from the plate edge to the midpoint of it and further passes through the plastic zone generated by Path 1 ; furthermore, when it reaches the edge of plastic zone of Path 1, load is terminated. According to Figure 5(d), Path 2 moves from one edge of the plate to the other.

Figure 3 shows that line rolling forming mainly gives rise to in-plane and bending strains that are perpendicular to forming path. By comparing maximum values of both strains, it becomes clear that bending strain plays a vital role as far as the established press amount of rollers is concerned. First, impacts of four crossed paths given in Figure 4 on variations of $\varepsilon_{2}^{b}$, the principal bending strain on Path 1 are investigated. Figure 6(a) signifies the principal bending strain $\varepsilon_{2}^{b}$ of plate section along Path 1. According to this figure, strain distribution changes significantly inside the crossed zone. To be specific, in Figure 6(a), in a condition of a single forming path, uniform and steady strains are generated by Path 1 and distributed on the plate. In the first state, residual stress generated by Path 1 makes $\varepsilon_{2}^{b}$ slightly declined; in the second state, $\varepsilon_{2}^{b}$ significantly goes down due to influences of the residual stress generated by Path 1 as well; likewise, in the third state, the residual stress generated by Path 1 brings $\varepsilon_{2}^{b}$ down substantially and such a decrease is more evident than the above two states; finally, in the fourth state, changes in $\varepsilon_{2}^{b}$ are basically consistent with those in the third state.

If graphics are drawn for the principal bending strain $\varepsilon_{2}^{b}$ along plate section of Path 2 mentioned above according to results of this path in diverse states, changing rules of these curves are similar to Figure 6(a).

The above results indicate that plastic strains generated by two forming paths successively can give rise to mutual influence in regions next to the residual stress remained in crossing points. In line with Figure 6(a), dimension of the influence region is less than $100 \mathrm{~mm}$; at the same time, it is clear that strain under the influence fluctuates slightly in the case that Path 2 cannot pass through Path 1 . Only when one forming path passes through another path, significant impacts can be exerted on the size of strain. However, dimension of such an influence region does not change because of the above phenomenon described and it is still confined in the scope of residual stress generated by Path 1 .

Path 1 is set at the midpoint of plate and is parallel to Path 2 with spacing $l$ equal to $100 \mathrm{~mm}$. Then, line rolling forming is conducted on the plate along two forming paths for numerical calculation and the result is presented in Figure 4(b). In this figure, strain distribution after machining can be acquired. If two forming paths act individually without coupling, strain distribution results under actions of them should be numeral superposition of strain distribution results under actions of two individual forming paths. Curves labeled as "Results without Coupling" in Figure 6(b) are results 


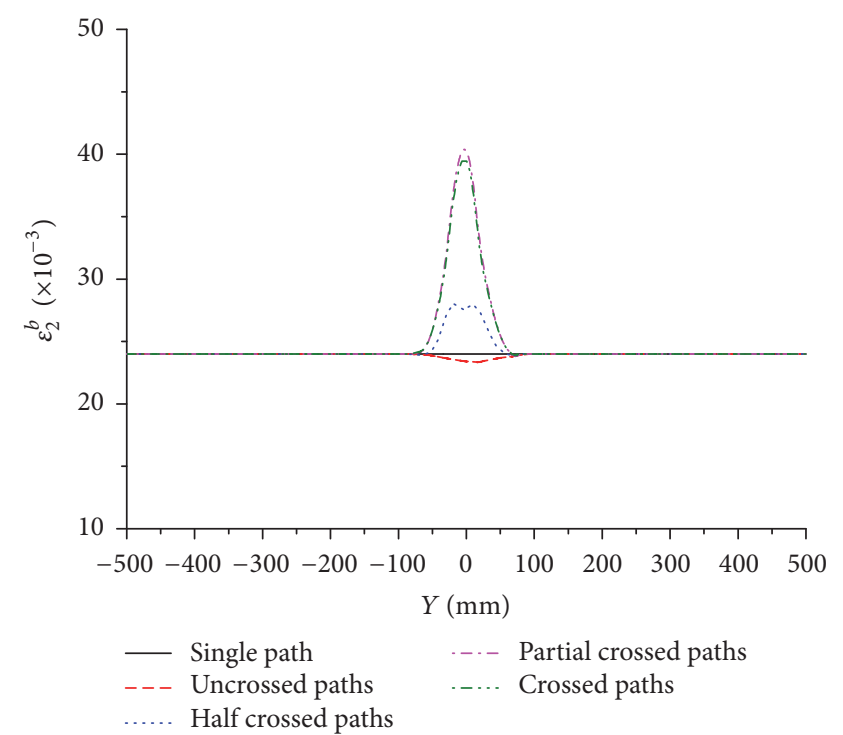

(a)

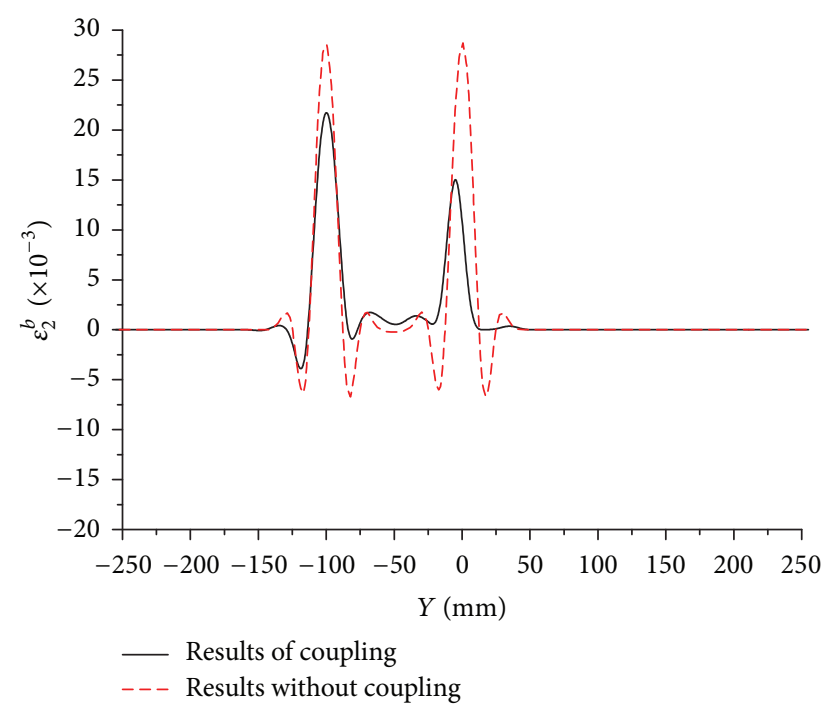

(b)

FIGURE 6: Influences of multichannel forming path on strain distribution. (a) Influences of crossed paths; (b) influences of parallel paths.

obtained by superposition of results under the action of a single forming path with those for the corresponding position on the other path. In the case that strain distribution results after the respective action of two forming path are referred to as "Results of Coupling," they are preferably correlated with each other in terms of their general strain distribution rules, despite certain differences in peak values the magnitude of which is arranged in a basically corresponding order. It can be deemed that two parallel forming paths of coupling only generate limited influences under the circumstance that the spacing is no less than $100 \mathrm{~mm}$. Therefore, it is feasible that strains are directly added to obtain the required strain distribution approximately.

For line rolling forming, plastic strain region generated by forming path is much narrower than the machined plate. An individual forming path is able to cause residual stress region to be mainly concentrated within a very small area near the loaded line. In general cases, spacing between forming paths is rather great. Therefore, coupling between forming paths can be neglected when the inherent strain method is adopted to predict the global deformation of machined plate. In other words, strains of all forming paths can be directly added together to obtain strain distribution on the entire plate, so as to achieve global deformation by an elastic calculation.

\section{Forecasting of Local Line Rolling Forming by Inherent Strain Method}

As a method developed fast in recent years, inherent strain method [8] can be used to implement prediction of large structural welding deformation or the line heating deformation $[9,10]$. This direction holds that inherent strain exists in weld (heating line) and around it, and the level and distribution of inherent strain decide welding (line heating) deformation and residual stress. So, structural stress and deformation can be identified if the relationship between the level and distribution of inherent strain and welding (line heating) heat input and construction size is determined, and inherent strain is applied to structure as an initial strain for an elastic finite element calculation. Compared with elastoplastic finite element, inherent strain can greatly reduce computational complexity to implement rapid prediction of welding (line heating) deformation. Since there is a similarity in plastic strain distribution between line rolling forming and line heating forming, both in-plane and bending strain are perpendicular stably to the forming path. Besides, the above results signify that influences of strain coupling generated during load on the global deformation can be ignored. Therefore, inherent strain method can be used for prediction of deformation in line rolling forming as in line heating forming.

Inherent strain equals the sum of plastic strain, heating strain, and transformation strain, but in line rolling forming, inherent strain is equal to plastic strain due to the lack of change in temperature. As can be seen in Figure 3, the plastic strain generated by line rolling forming is distributed stably in a long section, so the plastic strain within the stable section can be extracted and input into a computational model in the form of initial strain. Then plate deformation can be calculated after the iteration. This process is an elastic calculation procedure, and, for calculation, there needn't be high requirement for hardware and it is unnecessary to take much time. To further validate global deformation prediction accuracy of the inherent strain method applied in local line rolling forming calculations, the target shape with double curvature is selected for computing, as shown in Figure 7. Deflections of 231 nodes are presented in Table 2. Then, strain distribution from the plate to the target shape can be obtained by the elastic finite element method. In consistency with Figure 8(a), strains very easily determine the corresponding forming path that has been given in 


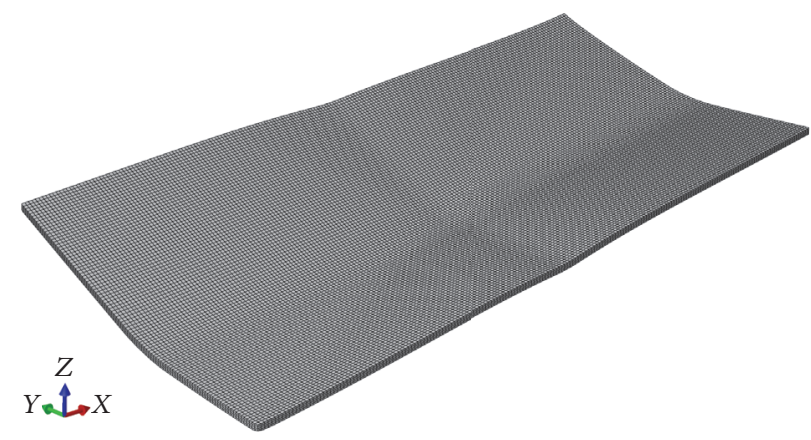

Figure 7: Target shape for forming.

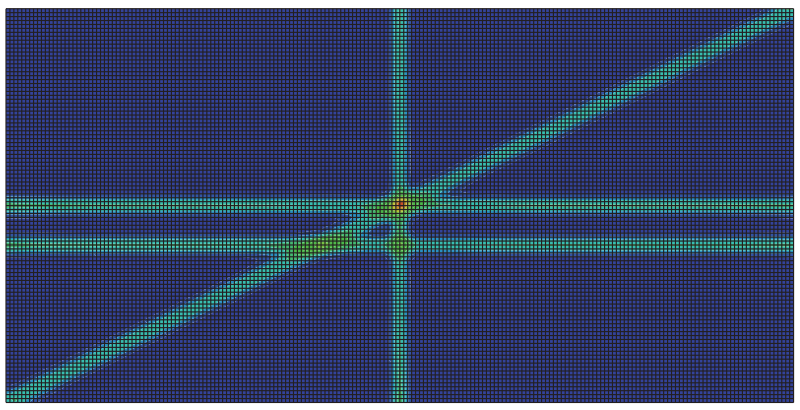

(a)

FIGURE 8: Determination of strain distribution and forming path. (a) Strain distribution for target shape forming; (b) forming paths determined according to strain distribution.

Figure 8(b). Evidently, there are four forming paths in total. However, the target shape selected for now contains several typical and representative forming paths of coupling.

The load of every forming path can be determined by strain distribution on this path, so as to define the strain distribution generated by forming paths on the plate. All strains generated on every forming path are simultaneously imposed to obtain strain distribution of the entire plate. Furthermore, the inherent strain method is utilized to achieve computing results of strains related. Then, these results are compared with target shapes shown in Table 1; the overall deviation between them can be worked out based on

$$
\sigma=\sqrt{\frac{\sum_{i=1}^{n} D_{i}^{2}}{n}},
$$

where $\sigma$ refers to the overall deviation, $n$ to the number of nodes, and $D_{i}$ to the minimum distance from node $i$ to the target shape.

The lower $\sigma$ is, the higher the curvature tolerance between the target shape and the global shape will be. On this basis, relative deviation between 231 nodes and those nodes corresponding to the target shape is calculated. Thus, the overall deviation of the target shape and the shape obtained by calculation based on the inherent strain method is about $1 \mathrm{~mm}(\sigma \approx 1 \mathrm{~mm})$. Moreover, the maximum relative deviation of single point is $5.5 \%$. It indicates that forming results figured out and predicted by the inherent strain method are very

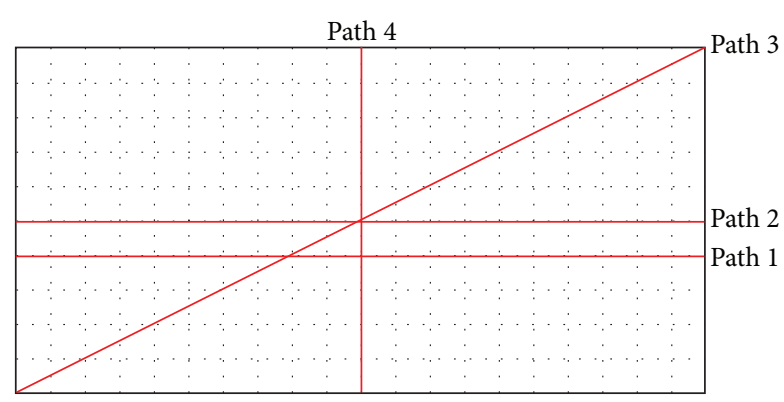

(b)

close to the given target shape. In other words, such an inherent strain method can be adopted to accurately predict deformation in local line rolling forming. In comparison with elastoplastic simulation, the inherent strain method only requires defining initial and end point coordinates as well as initial strain of each forming path to perform one elastic finite element calculation. Thus, preparations and time needed by general numerical calculations can be dramatically reduced. In addition, computational efficiency of the inherent strain method is far higher than the elastoplastic finite element method. Regarding double curvature plate line rolling forming numerical calculation presented in Table 1, the elastoplastic simulation method requires hundreds of hours, while the inherent strain method needs only ten minutes. That is about $1 \%$ of the time consumed by calculations based on the elastoplastic finite element method. If a database is set up for relations between plastic strains and load parameters, deformation in line rolling forming can be obtained based on the inherent strain method in a more accurate and rapid manner.

\section{Conclusions}

(1) Line rolling forming generates plastic strain along and around the forming path of plate, and plastic strain is stable along the rolling path. Line rolling forming can generate in-plane strain and bending strain simultaneously, among which bending strain plays a dominant role. 
TABLE 2: Node deformation of target shape for forming (unit: $\mathrm{mm}$ ).

\begin{tabular}{lcccccccccccccccccccccc}
\hline$Y$ & & 1000 & -900 & -800 & -700 & -600 & -500 & -400 & -300 & -200 & -100 & 0 & 100 & 200 & 300 & 400 & 500 & 600 & 700 & 800 & 900 & 1000 \\
\hline-500 & 0 & -4 & -5 & -5 & -5 & -5 & -5 & -5 & -5 & -7 & -9 & -6 & -3 & -1 & 0 & 0 & 0 & 0 & 0 & 0 & 0 \\
-400 & -13 & -18 & -21 & -23 & -23 & -22 & -22 & -22 & -22 & -24 & -26 & -23 & -20 & -18 & -18 & -17 & -17 & -17 & -17 & -17 & -17 \\
-300 & -25 & -29 & -33 & -36 & -39 & -39 & -39 & -38 & -39 & -40 & -42 & -39 & -37 & -35 & -35 & -35 & -35 & -35 & -34 & -34 & -34 \\
-200 & -35 & -39 & -43 & -46 & -49 & -52 & -54 & -55 & -55 & -56 & -58 & -55 & -53 & -53 & -52 & -52 & -52 & -52 & -51 & -51 & -50 \\
-100 & -44 & -48 & -51 & -55 & -58 & -61 & -63 & -66 & -69 & -71 & -73 & -70 & -69 & -69 & -68 & -68 & -68 & -68 & -67 & -67 & -65 \\
0 & -45 & -48 & -52 & -55 & -58 & -61 & -64 & -67 & -70 & -74 & -79 & -78 & -77 & -77 & -77 & -76 & -76 & -76 & -75 & -74 & -73 \\
100 & -37 & -40 & -44 & -47 & -50 & -53 & -56 & -59 & -63 & -68 & -74 & -75 & -77 & -77 & -77 & -76 & -76 & -76 & -75 & -74 & -73 \\
200 & -28 & -31 & -34 & -37 & -40 & -43 & -47 & -50 & -55 & -60 & -67 & -68 & -70 & -73 & -75 & -75 & -75 & -74 & -74 & -73 & -72 \\
300 & -19 & -22 & -25 & -28 & -31 & -34 & -38 & -42 & -46 & -52 & -59 & -60 & -62 & -64 & -67 & -70 & -73 & -73 & -72 & -71 & -70 \\
400 & -9 & -13 & -16 & -19 & -22 & -25 & -28 & -33 & -38 & -44 & -51 & -52 & -54 & -56 & -59 & -62 & -65 & -67 & -69 & -68 & -66 \\
500 & 0 & -3 & -6 & -9 & -12 & -15 & -19 & -23 & -29 & -35 & -42 & -44 & -45 & -47 & -50 & -53 & -56 & -58 & -60 & -61 & -60 \\
\hline
\end{tabular}

(2) Inherent strain method can be used to forecast the deformation caused by line rolling forming, and compared with elastoplastic finite element method, it can improve the computational efficiency and ensure the deformation precision.

(3) The inherent strain method used for line heating forming of plate is also applicable to calculating continuous mechanical loads with line features.

\section{Conflicts of Interest}

The authors declare that there are no conflicts of interest regarding the publication of this paper.

\section{Acknowledgments}

This work was supported by the Ministry of Science and Technology of the People's Republic of China Grant no. 2012DFR80390 and by the Natural Science Foundation of Hubei Province Grant no. 2011CDA031. The authors wish to thank Professor Kirill Rozhdestvensky of State Marine Technical University of St. Petersburg for useful academic and constructive advices during the project.

\section{References}

[1] E. W. Reutzel, L. Zhang, and P. Michaleris, "A differential geometry approach to analysis of thermal forming," International Journal of Mechanical Sciences, vol. 48, no. 10, pp. 1046-1062, 2006.

[2] T. Wang, M. J. Platts, and A. Levers, "A process model for shot peen forming," Journal of Materials Processing Technology, vol. 172, no. 2, pp. 159-162, 2006.

[3] G. Ambrogio, "Application of incremental forming process for high customized medical product manufacturing," in Proceedings of the 8th International Conference on Advances in Materials and Processing Technologies (AMPT '05) and 13th International Scientific Conference on Achievements of Mechanical and Materials Engineering (AMME '05), Elsevier, Wisla, Poland, May 2005.

[4] A. Vega, Y. Tango, M. Ishiyama, S. Rashed, and H. Murakawa, "Influential factors affecting inherent deformation during plate forming by line heating (Report 3)-the effect of crossed heating lines," in Proceedings of the 18th International Offshore and Polar Engineering Conference (ISOPE '08), pp. 301-308, Vancouver, Canada, July 2008.

[5] H. Murakawa, Y. Luo, and Y. Ueda, "Prediction of welding deformation and residual stress by elastic FEM based on inherent strain (first report) mechanism of inherent strain production," Journal of the Society of Naval Architects of Japan, vol. 180, pp. 739-751, 1996.

[6] Q. S. Kong, "Flexible roll forming with staggered arranged rollers for the large curved metal plates based on numerical simulation," in Proceedings of the 11th International Conference on Numerical Methods in Industrial Forming Processes, Shenyang, China, July 2013.

[7] S. J. Yoon and D. Y. Yang, "Development of a highly flexible incremental roll forming process for the manufacture of a doubly curved sheet metal," CIRP Annals-Manufacturing Techno$\log y$, vol. 52, no. 1, pp. 201-204, 2003.

[8] Y. Ueda, Y. C. Kim, and M. G. Yuan, "A predicting method of welding residual stress using source of residual stress (report i) : characteristics of inherent strain (source of residual stress)(mechanics, strength \& structural design)," Transactions of JWRI, vol. 18, no. 1, pp. 135-141, 1989.

[9] H. Murakawa, D. Deng, N. Ma, and J. Wang, "Applications of inherent strain and interface element to simulation of welding deformation in thin plate structures," Computational Materials Science, vol. 51, no. 1, pp. 43-52, 2012.

[10] L. L. Lin, "Inherent strain analysis of thin-walled structure welding deformation," Applied Mechanics and Materials, vol. 385386, pp. 117-120, 2013. 


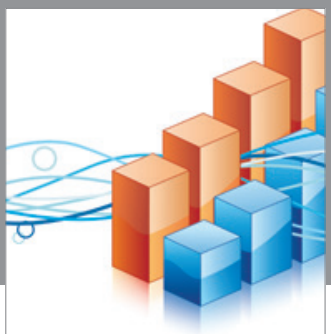

Advances in

Operations Research

vatem alat4

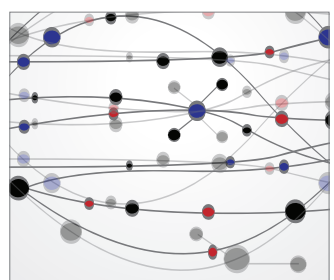

\section{The Scientific} World Journal
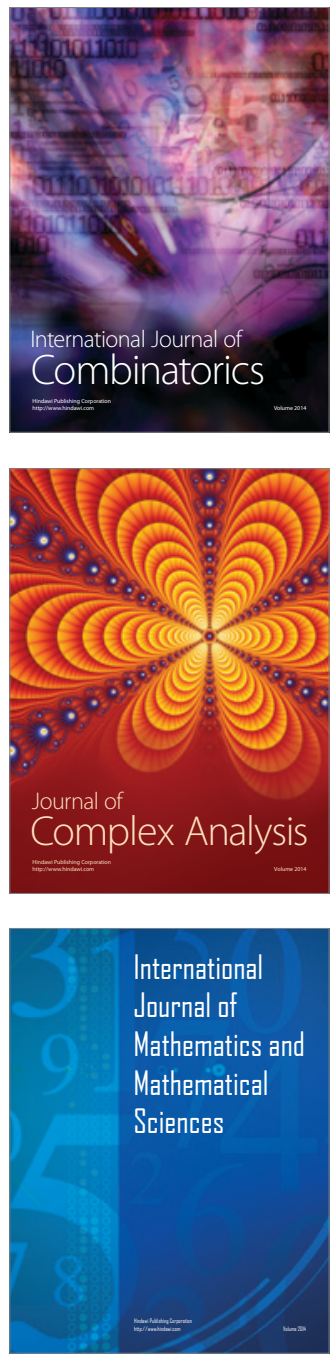
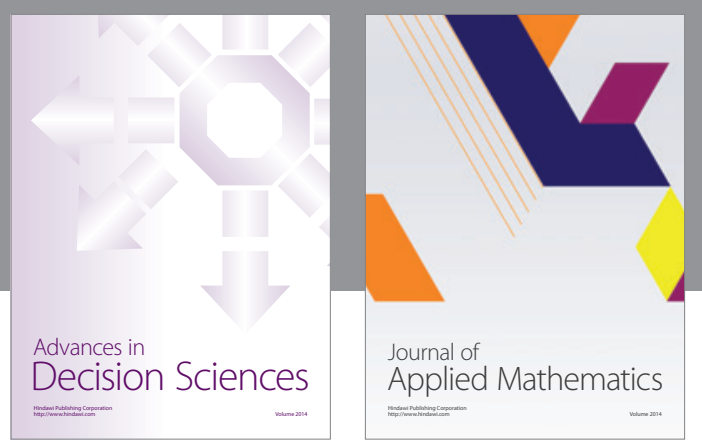

Algebra

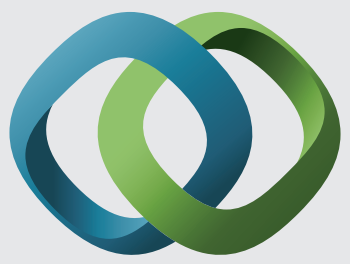

\section{Hindawi}

Submit your manuscripts at

https://www.hindawi.com
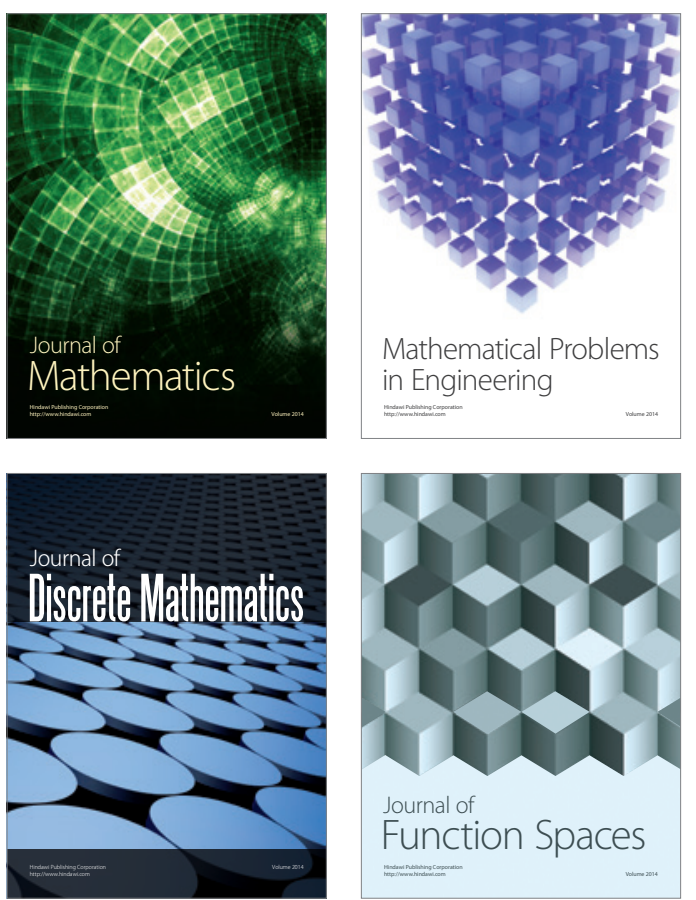

Mathematical Problems in Engineering
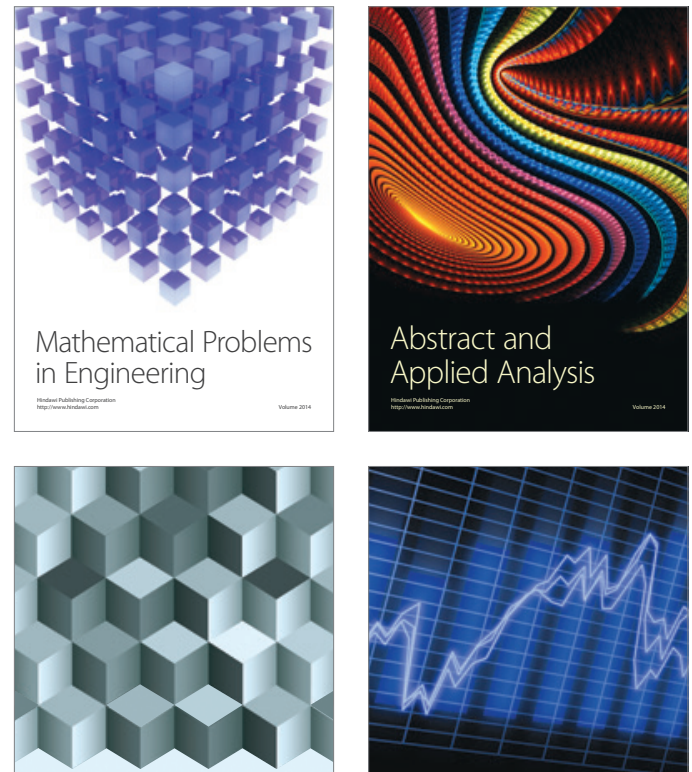

Journal of

Function Spaces

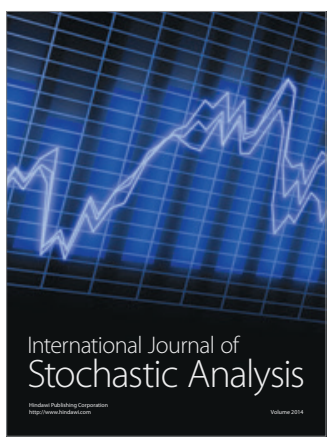

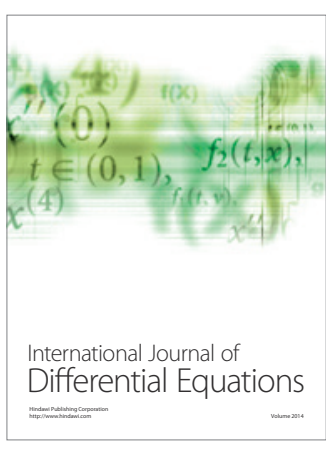
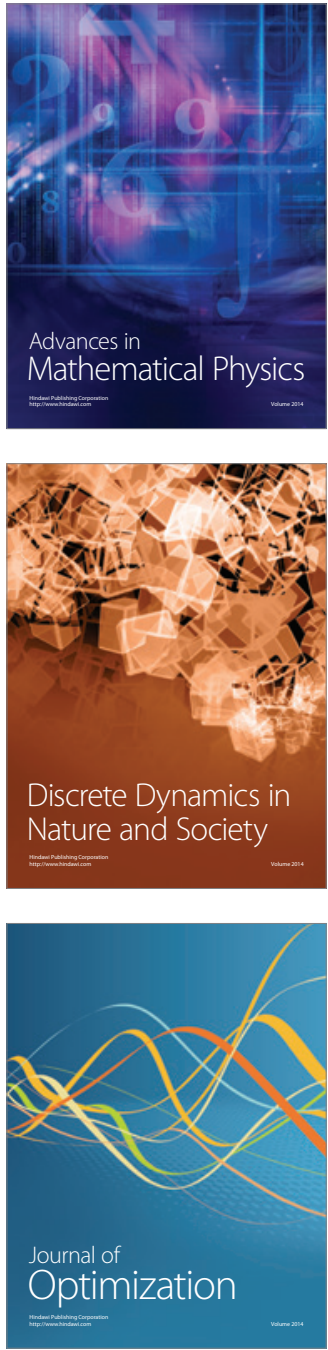